\title{
PROJETO CRAZY STORIES: a interdisciplinaridade no ensino de inglês como língua adicional. ${ }^{8}$
}

\section{CRAZY STORIES: an interdisciplinary project for the teaching of english as an additional language}

\author{
Fernando Vanzin de Gasperi ${ }^{9}$ \\ Anamaria Kurtz de Souza Welp ${ }^{10}$
}

\begin{abstract}
RESUMO: Os projetos interdisciplinares têm sido apontados como práticas desejáveis para o desenvolvimento de conhecimento relevante para os alunos por aproximar o conteúdo a sua realidade. Nessa perspectiva, este artigo relata a experiência com o desenvolvimento de um projeto pedagógico interdisciplinar, desenvolvido nas disciplinas de inglês e artes, durante o estágio de docência em língua inglesa, em uma turma de sexto ano de uma escola da rede pública de educação básica da região metropolitana de Porto Alegre, RS. A turma escolhida para a realização do projeto era composta por 26 alunos, com idades entre 11 e 15 anos, para os quais a disciplina de inglês seria oferecida pela primeira vez. O trabalho desenvolvido contou com a colaboração das professoras de inglês e artes. Apesar de a professora de inglês informar que utilizava o livro didático Alive!, autorizou a utilização do material especialmente elaborado para o projeto aqui descrito. A sequência didática foi planejada dentro da abordagem de projetos de trabalho, uma proposta colaborativamente construída e organizada com a participação de professores e alunos. Schlatter \& Garcez (2012) sugerem a organização do currículo por eixos temáticos para o favorecimento do trabalho interdisciplinar. Para os autores, as metas e o compromisso do ensino na escola são promover o autoconhecimento, o letramento e a interdisciplinaridade para que os alunos possam participar de discursos que se organizam a partir da escrita em português e em inglês. O projeto aqui descrito foi planejado e desenhado previamente, mas construído aula a aula, culminando na encenação de um texto teatral, escrito pelos alunos, e em um livro contendo as histórias encenadas. O projeto foi desenvolvido em 11 aulas de inglês e três aulas de artes. Este artigo apresenta o desenvolvimento do projeto e, com base nos estudos sobre interdisciplinaridade e educação por projetos, apresenta reflexões sobre seu desenvolvimento.
\end{abstract}

PALAVRAS-CHAVE: Língua adicional. Educação por projetos. Interdisciplinaridade. Sequência didática.

ABSTRACT: Interdisciplinary projects have been identified as desirable practices for the development of relevant knowledge for students by bringing content closer to their reality. In this perspective, this article reports the experience with the development of an interdisciplinary pedagogical project, developed in the English and Arts subjects, during the English as an Additional Language Teaching Practicum in a sixthgrade class at a public school in the metropolitan region of Porto Alegre, RS. The group chosen for the project was composed of 26 students, aged between 11 and 15 years, for whom the English course would be offered for the first time. The work was conducted with the collaboration of the English and Arts teachers. Although the English teacher reported using the Alive!4 textbook, she authorized the use of specially designed material for the project described here. The didactic sequence was planned within the Project Work approach, a proposal collaboratively constructed and organized with the participation of teachers and students. Schlatter \& Garcez (2012) suggest the organization of the curriculum by thematic axes to favor interdisciplinary work. For the authors, the goals and the responsibility of the teaching at schools are to promote self-knowledge, literacy, and interdisciplinarity so that students can participate in discourses that are organized from writing in Portuguese and in English. The project described here was planned and designed beforehand, but it was built lesson by lesson, culminating in the performance of a theatrical text, written by the students, and in a book containing the stories performed. The project was developed in 11 English classes and three Arts classes. This article presents the development of the project and the reflections that emerged from its development.

KEYWORDS: Additional language. Project based learning. Interdisciplinarity. Didactic sequence.

\footnotetext{
${ }^{8}$ Apresentado ao Instituto de Letras como requisito parcial para obtenção do título de Licenciado em Letras.

${ }^{9}$ Licenciado em Letras - Inglês pela Universidade Federal do Rio Grande do Sul. Email:

fernando.degasperi@yahoo.com.br

${ }^{10}$ Doutora em Letras e professora do Departamento de Línguas Modernas da Universidade Federal do Rio Grande do Sul. Email: anamaria.welp@ufrgs.br
} 


\section{Introdução}

A interdisciplinaridade é frequentemente apontada como uma prática desejável no ensino. A linguagem, por sua vez, é sabidamente uma das formas de se ter acesso às informações do mundo. Dessa forma, o trabalho com a língua na escola (seja língua materna ou adicional) pode facilitar uma abordagem interdisciplinar, dando acesso a conhecimentos de diversas áreas do saber. Nesse contexto, este artigo descreve a construção e aplicação de um projeto de aprendizagem de inglês como língua adicional (LA $)^{11}$, com vistas à produção de uma cena teatral, durante o estágio de docência em língua inglesa, em uma turma de sexto ano de uma escola da rede pública de educação básica da região metropolitana de Porto Alegre, RS. A sequência didática produzida para as aulas de inglês teve por objetivo dialogar interdisciplinarmente com o componente curricular artes, com vistas a capacitar os alunos para utilizarem a língua inglesa em situações do cotidiano escolhidas por eles, desenvolver seu letramento e sua consciência visando ampliar sua participação em diversas práticas sociais em que a língua inglesa é utilizada e analisar a plausibilidade do trabalho interdisciplinar na escola em que o projeto foi aplicado.

\section{A interdisciplinaridade e a pedagogia de projetos}

A sequência didática desenvolvida e examinada encaixa-se em um tipo interdisciplinar de abordagem, a pedagogia de projetos. Portanto, cabe analisar previamente o que se entende por esses termos e o que se espera atingir quando se pauta a prática docente nessas teorias.

\subsection{Interdisciplinaridade, transdisciplinaridade e transversalidade}

A abordagem interdisciplinar tem sido bastante discutida, com críticos apontando aspectos positivos e negativos de seu uso (ou eficácia) para o ensino. Para construir um projeto interdisciplinar pertinente, convém entender quais são as vantagens e os limites dessa prática.

Para Gallo (1995), a interdisciplinaridade é uma forma de organizar os currículos escolares de modo a possibilitar integração entre as disciplinas. Nessa perspectiva, segundo ele, cada disciplina compõe um campo de especialização e a abordagem interdisciplinar busca integrar esses campos. Tais campos de especialização são resultado da produção, pelo homem, de tecnologias do conhecimento, ou aparatos que permitem que o homem examine aspectos da realidade que deseja transformar em objeto de estudo. Essas tecnologias, porém, influenciam o próprio processo de construção do conhecimento, tornando-o cada vez mais especializado e ensejando a constituição de disciplinas específicas e independentes. $\mathrm{Na}$ educação, organizar o saber em disciplinas pode, por um lado, facilitar o acesso dos estudantes a esses saberes e tornar o professor um especialista na área. Por outro lado, alunos e professores não são capazes de vislumbrar conexões entre as disciplinas (GALLO, 1995).

Edgar Morin, filósofo conhecido pela teoria da complexidade, critica a departamentalização das disciplinas, considerando inclusive ser esse um dos problemas centrais da educação (MORIN, 2000). Isso ocorre porque a hiperespecialização (isto é, a especialização que se fecha sobre si mesma) impede que se criem as condições para um conhecimento pertinente, ou seja, um conhecimento que não mutile seu objeto. Afinal, não é a quantidade de informações ou a especialização em determinada área que resulta em conhecimento pertinente, mas a capacidade de colocar o conhecimento em contexto. Dentro de disciplinas hiperespecializadas, o objeto de estudo é retirado de seu contexto, mutilado e, portanto, incapaz de produzir um conhecimento pertinente:

11 Com base em Schlatter \& Garcez (2009), optamos pelo termo “língua adicional”, utilizando "língua estrangeira" apenas quando os autores citados assim preferiram. 
Como nossa educação nos ensinou a separar, compartimentar, isolar e, não, a unir os conhecimentos, o conjunto deles constitui um quebra-cabeças ininteligível. [...] Os grandes problemas humanos desaparecem em benefício dos problemas técnicos particulares. A incapacidade de organizar o saber disperso e compartimentado conduz à atrofia da disposição mental natural de contextualizar e de globalizar. (MORIN, 2000, p. 42)

Para representar a estrutura tradicional da especialização das disciplinas, Gallo (1995 e 2007) utiliza o paradigma arbóreo, que encara o conhecimento como uma grande árvore que tem por tronco a Filosofia, de onde se especializam os demais saberes - que só podem ligar-se mediante o tronco. Por analogia, disciplinas diferentes podem se comunicar apenas através de áreas comuns. Na educação, o problema é que os estudantes, após aprenderem disciplinarmente, não conseguem recuperar o todo. Na busca dessa totalidade estão os esforços interdisciplinares.

Entretanto, uma vez fragmentados os saberes, a interdisciplinaridade, enquanto simples ligação, não é capaz de reconstituí-los, o que acaba por delimitar ainda mais as fronteiras de cada disciplina. $\mathrm{Na}$ analogia de Morin (2005, p. 135), a interdisciplinaridade está para as disciplinas assim como a ONU está para as nações, em um nível hierárquico superior e com a função de integrar e controlar o nível inferior. Ou seja, mesmo que a interdisciplinaridade vença as resistências de sua aplicação (no que se refere a planejamento, engajamento de estudantes e professores, recursos humanos e materiais necessários à conexão dos saberes, entre outros), ela não vence a compartimentalização dos saberes.

Para superar tal compartimentalização é necessário adotar um novo paradigma de representação do conhecimento: o paradigma rizomático (GALLO, 1995 e 2007). Essa representação, baseada em Deleuze e Guattari, evoca a imagem do rizoma e pressupõe uma relação intrínseca entre as inúmeras áreas do saber. Ou seja, não há unidade superior que controla unidades inferiores assim como não há campos distintos de saber que se comunicam através de um único meio; o que existe é uma pluralidade de caminhos e conexões. Essa pluralidade tem sido chamada de transversalidade. Transversalidade refere-se ao modo de "trânsito" entre os saberes, de modo que transdisciplinar será a abordagem que permita esse trânsito. Enquanto a interdisciplinaridade se refere à integração entre as disciplinas na busca pela unidade (pelo Todo), a transversalidade rizomática aponta para a pulverização e, em vez de integrar as disciplinas, estabelece policompreensões infinitas (GALLO, 1995, p. 7).

Para Morin (2005, p. 138), é necessário uma transdisciplinaridade que permita

distinguir, separar, opor e, portanto, dividir relativamente esses domínios científicos,
mas que possa fazê-los comunicarem sem operar a redução. O paradigma que
denomino simplificação (redução/separação) é insuficiente e mutilante. É preciso
um paradigma de complexidade, que, ao mesmo tempo, separe e associe, que
conceba os níveis de emergência da realidade sem os reduzir às unidades
elementares e às leis gerais.

Dessa forma, o pensamento de Morin alinha-se à representação rizomática do conhecimento, inclusive pela forma de comunicação entre os saberes, que ele sugere pelo enraizamento. Operar o enraizamento difere de operar a redução, uma vez que não se reduz o objeto de estudo a interações descontextualizadas, mas se reconhece níveis de emergência da realidade.

Produzir conhecimento pertinente implica reconhecer que o objeto de estudo está inserido em uma realidade complexa. E o problema da complexidade, conforme seu teórico mais influente, não é o da completude, mas o da incompletude do conhecimento. A complexidade é aquilo que tenta conceber a articulação, a identidade e a diferença entre diversos aspectos (biológicos, sociais, psicológicos, culturais, espirituais, físicos), enquanto o pensamento simplificante separa esses diferentes aspectos ou unifica-os por uma redução 
mutilante (MORIN, 2005). Na transversalidade, a produção e a circulação do conhecimento entre os saberes se dá de forma caótica, livre e não hierárquica, diminuindo as fronteiras entre as disciplinas. $\mathrm{O}$ quadro 1 resume e compara os três conceitos discutidos acima.

\begin{tabular}{|l|l|}
\hline Interdisciplinaridade & $\begin{array}{l}\text { - Promove a integração entre as disciplinas, cada uma delas um } \\
\text { campo de especialização; } \\
\text { - remete ao paradigma arbóreo da representação do conhecimento; } \\
\text { - promove a integração das disciplinas na busca pela unidade; } \\
\text { - é hierarquicamente superior às disciplinas, controlando-as; } \\
\text { - não vence a compartimentalização dos saberes; }\end{array}$ \\
\hline Transdisciplinaridade & $\begin{array}{l}\text { - Divide os domínios científicos sem operar a redução; } \\
\text { - remete ao paradigma rizomático da representação do conhecimento; } \\
\text { - não busca a simples integração entre as disciplinas; busca a } \\
\text { pulverização (estabelecendo multicompreensões infinitas); } \\
\text { - não há unidade hierárquica; } \\
\text { - estabelece relações intrínsecas entre as áreas do saber. }\end{array}$ \\
\hline Transversalidade & $\begin{array}{l}\text { - Promove a pluralidade de caminhos e conexões entre os saberes; } \\
\text { - objetiva o trânsito livre, caótico e desordenado entre os campos do } \\
\text { saber; } \\
\text { - não estabelece fronteiras entre as disciplinas. }\end{array}$ \\
\hline
\end{tabular}

Quadro 1 - Interdisciplinaridade, transdisciplinaridade e transversalidade

A implementação de uma abordagem transdisciplinar esbarra, porém, na própria estrutura do ensino escolar, que é centrado nas disciplinas, em currículos especializados, com pouca abertura para interação entre as áreas. Por essa razão, o projeto relatado aqui será tratado como interdisciplinar, já que as áreas de conhecimento são previamente definidas (inglês e artes), inclusive com separação rigorosa de períodos e horários.

\subsection{A pedagogia de projetos}

Uma das maneiras de buscar um conhecimento pertinente, mesmo dentro de um ensino pautado por disciplinas, é através da pedagogia de projetos. Segundo Hernandez (2014), a perspectiva de educação por projetos de trabalho (PEPT) permite que o aprendizado ocorra no diálogo e na indagação. A PEPT não é uma fórmula fixa e pronta para adoção pelos professores; é uma proposta que se compartilha aos poucos e que se realiza junto com os alunos, sob pena de não ter sentido. Assim, não se trata os projetos "como uma técnica didática na qual se aplica uma sequência de passos partindo do que se diz serem os interesses dos meninos e meninas e dos adolescentes" (HERNANDEZ, 2001, p. 2). Para o autor, conforme citado em WELP \& VIAL (2016, p. 192):

a Perspectiva Educativa de Projetos de Trabalho (PEPT) é uma visão a respeito das relações pedagógicas e do aprendizado por meio do diálogo e da indagação. Para o pesquisador, o ideal é que a vida da sala de aula e da escola seja um projeto em que todos os envolvidos encontrem seu lugar para aprender. $\mathrm{O}$ foco nessa perspectiva é promover transformações que mudam não só as relações, mas também o sentido da escola e o lugar dos sujeitos. Nesse processo, docentes e estudantes têm um papel protagonista, pois entendem-se como autores que geram conhecimento e saber pedagógico.

Esse processo, para Barbosa (2001), não é inflexível, já que comporta uma gama de variáveis e percursos imprevisíveis, imaginativos, criativos e inteligentes, com grande 
flexibilidade de organização. Isso significa que não existe uma maneira rígida de implementar projetos. $\mathrm{Na}$ verdade, o projeto não deve ser implementado (de cima para baixo), mas construído com a participação dos envolvidos. E por isso a importância do diálogo e da indagação como essenciais dentro dessa perspectiva de ensino. É através da indagação que o projeto encontra seu rumo, assim como troca de rumo, às vezes. E através do diálogo é que se constrói esse caminho.

Para Simões (2012), é preciso atentar para a participação do aluno no processo de aprendizagem e, para isso, os projetos devem fazer sentido para os estudantes. E isso é um trabalho a ser construído em aula. Deve-se buscar um currículo escolar integrado e interdisciplinar para o tratamento de questões importantes no presente, dos alunos e da sociedade. A ideia é que os projetos escolares são uma excelente forma de organizar o currículo para um tratamento problematizador e interdisciplinar.

Dada a flexibilidade do trabalho com projetos, pode haver certa instabilidade em seu desenrolar. Hernandez (2014) não considera esse aspecto como negativo, já que o planejamento do projeto será continuamente aprimorado, modificado, para satisfazer as necessidades de aprendizagem dos participantes. Barbosa (2001) atribui a insegurança dos educadores com essa pedagogia ao fato de que eles não podem ter, desde o início, o mapeamento do projeto como um todo, já que este será construído na ação, paulatinamente.

\subsection{Projetos interdisciplinares no ensino de LA}

De acordo com Schlatter \& Garcez (2012), a escola precisa ser redimensionada para que reafirme a sua função social de possibilitar mudanças, face ao mundo e às metas educacionais contemporâneas. Dentro do currículo de LA, as metas e o compromisso do ensino na escola são promover o autoconhecimento, o letramento e a interdisciplinaridade para que os alunos possam participar de discursos que se organizam a partir da escrita em português e em inglês. $\mathrm{O}$ autoconhecimento refere-se a capacidade de contextualizar o que é aprendido, fazendo relações entre a própria realidade e a realidade do outro. Promover o letramento é, na definição de Schlatter (2009, p. 12), promover "a participação em diferentes práticas sociais que envolvem a leitura e a escrita na língua materna e na LE". A proposta de Schlatter \& Garcez (2012) avança ao sugerir o texto como central ao processo de letramento e ao tornar curricular o trabalho de projetos interdisciplinares.

Para Biondo (2012, p. 249), letramento refere-se ao "desenvolvimento social da escrita como um todo, envolvendo as práticas sociais e os impactos que a escrita exerce em uma sociedade". A promoção da interdisciplinaridade, por sua vez, procura conectar disciplinas em torno de uma temática comum. Dentro desse contexto, os conteúdos de ensino e avaliação em LA focalizam o letramento, que ocorrerá de maneira contextualizada (promovendo, assim, o autoconhecimento) e mobilizando saberes de outras áreas. Para atingir tais metas, sugere-se o trabalho com projetos. Para Hernandez (2014), os projetos podem (ou não) incluir abordagens interdisciplinares, dependendo das indagações que os norteiam. Ele aponta que a aprendizagem se dá na construção de relações com sentido e que essas relações podem ocorrer dentro do limite das disciplinas ou não, extrapolando-as. Dessa forma, para ele, não há necessidade de rotular. De qualquer forma, o objetivo do projeto é produzir um conhecimento relevante e contextualizado, e a interdisciplinaridade pode ser usada com esse fim.

Para projetos interdisciplinares, então, há de se tomar "decisões interdisciplinares gerais (eixo temático e problematização e, em alguns casos, também textos comuns)" (SCHLATTER \& GARCEZ,2012, p. 71). Isso significa que os professores que pretendem trabalhar de forma interdisciplinar precisam dialogar para escolher qual será o eixo temático, isso é, sobre o que será o projeto e qual sua problematização, ou seja, que questões ele persegue. Definidas essas questões, podem ser pensados textos comuns, em conjunto ou não, que estruturarão o projeto. 
Estruturar os projetos e as aulas de LA nos textos e gêneros do discurso, e não mais em listas de tópicos gramaticais descontextualizados, requer esclarecer alguns pontos. O primeiro deles é que o texto não faz sentido como objeto linguístico descontextualizado, pois é sempre produzido por alguém, para alguém e com um propósito específico. Também há de se esclarecer que texto refere-se tanto a interlocuções escritas quanto orais, em infinitos modos de organizar o uso da língua (SCHLATTER, 2009; SIMÕES, 2012,). Assim, seu conceito pode abranger uma conversa informal ou um discurso presidencial, um bilhete ou um romance. A compreensão do texto exige que se pense sua contextualização.

O objetivo, porém, não é apenas conhecer e classificar os gêneros e sim oportunizar a prática do educando com textos na posição de interlocutor e de autor, já que a aprendizagem dos gêneros ocorre através de oportunidades de participação com os textos que fazem parte do gênero. É preciso ter oportunidade de prática para poder bem compreender os textos, atuando sobre eles. Tal prática também será a responsável pelo desenvolvimento do letramento, visto que esse conceito "costuma fazer referência a práticas que envolvem a leitura, a escrita e a oralidade em lugares e condições distintas, contemplando não somente o meio escolar, mas também contextos diversos nos quais múltiplas práticas de uso da linguagem podem se realizar" (BIONDO, 2012, p. 248).

Assim, compreender um texto (e consequentemente desenvolver letramento) é mais que saber suas estruturas gramaticais. Nessa perspectiva, a apresentação de formas linguísticas depende das demandas surgidas ao tentar-se ler os textos para avançar no projeto. Assim, o propósito de uma aula de inglês, ao apresentar recursos linguísticos específicos, estará a serviço da compreensão e da produção de textos, possibilitando a participação do educando nos projetos pedagógicos planejados em conjunto (SCHLATTER \& GARCEZ, 2012).

\subsection{Elaboração de sequências didáticas}

Uma sequência didática é o conjunto de atividades escolares organizadas, de maneira sistemática, em torno de um gênero textual oral ou escrito e tem por finalidade auxiliar o aluno a dominar melhor um gênero de texto ${ }^{12}$ (DOLZ et al 2004). As sequências didáticas servem, ainda, para dar acesso aos alunos a práticas de linguagem novas ou dificilmente domináveis. De acordo com Schlatter e Garcez (2009), a sequência didática apresenta tarefas que se justificam em torno da confecção do produto final. Dessa forma, em cada tarefa da sequência o projeto deve nortear o trabalho, definindo os objetivos de leitura e de produção linguísticas.

A sequência didática deve promover práticas que partam das interações mais simples para as mais complexas com vistas à elaboração do produto final, através de: tarefas preparatórias para a leitura, tarefas de estudo do texto, tarefas de preparação para a elaboração do produto final e tarefas de elaboração e apresentação do produto final.

As tarefas preparatórias apresentam os conhecimentos prévios que os alunos precisam acessar para iniciar o trabalho e compreender os textos necessários ao projeto. As tarefas de estudo do texto compreendem o contato inicial com o texto, analisando o gênero do discurso (quem fala, para quem, com que finalidade, etc.) e as formas de interpretá-lo. Compreendem, ainda, formas de reação ao texto, momentos de produção do aluno, o qual se torna interlocutor real daquele texto. A preparação para a elaboração do produto final é consequência das reações aos textos estudados nas tarefas anteriores e objetiva fornecer aos alunos os instrumentos necessários para elaborar o produto final. Se nas tarefas de estudo do texto os

\footnotetext{
12 Dolz et al (2004) utilizam a expressão "gênero de texto" enquanto Schlatter \& Garcez (2009) utilizam "gênero do discurso". Neste artigo, optamos por usar "gênero do discurso", conforme Dias et al (2011), mantendo "gênero de texto" apenas para os autores que assim preferiram.
} 
alunos usavam a língua para compreender os textos do projeto e reagir a eles, esta etapa marca a transição para a criação do produto final próprio dos alunos. Para a fase de elaboração do produto final, os alunos já possuem conhecimento relacionado ao que desenvolverão (trabalhado nas tarefas anteriores) e começam a preparar seu próprio produto final. Finalmente, há de se apresentar o produto final, em interlocução efetiva com outros sujeitos. Essa etapa permite aos alunos concretizar a interação com os outros e ter a dimensão da sua habilidade e possibilidade do uso da língua adicional para expressar-se.

Ainda segundo Schlatter \& Garcez (2012), em todas as etapas os alunos devem mobilizar as competências e habilidades que compõem as práticas de ler, escrever e resolver problemas, de maneira integrada. Isso é, a cada etapa os alunos conhecem melhor o tema e o gênero de discurso com o qual estão lidando, avançando assim na produção final. Para isso, também é fundamental o trajeto uso-reflexão-uso, ou seja, "o ponto de partida é o que os alunos já fazem e sabem fazer, para, então, se passar à reflexão e à ampliação dos seus repertórios e, por fim, a novos desafios" (SCHLATTER \& GARCEZ, 2009, p. 147).

\section{Contexto da pesquisa}

A escola onde o projeto foi realizado pertence à rede estadual, situa-se na Zona Norte de Porto Alegre, oferece ensino fundamental na modalidade regular e também Educação de Jovens e Adultos (EJA) e atende alunos de classe média baixa nos turnos manhã, tarde e noite. Possui biblioteca, sala de informática, sala de vídeo e uma quadra de esportes aberta.

A direção mostrou-se muito acessível e familiarizada com a proposta de projetos. À época da pesquisa, os alunos estavam, inclusive, engajados em uma gincana relacionada aos Jogos Olímpicos que envolvia diversas disciplinas e diferentes produções.

Antes do início das aulas do projeto, foram observados cinco períodos, tanto de aulas de inglês como de artes, da turma em que a sequência didática seria desenvolvida. O objetivo das observações era conhecer melhor a turma e sua relação com diferentes professoras e disciplinas.

As professoras de inglês e artes foram bastante receptivas com o projeto e se dispuseram a responder um questionário informando o curso e universidade em que haviam se formado, outras escolas em que haviam trabalhado, o número de horas trabalhadas na escola onde foi realizado o projeto, o número de horas total de trabalho, a opinião sobre a turma em sua disciplina e a organização das aulas. Informaram, ainda, se já haviam realizado trabalho interdisciplinar. Embora o programa das aulas de língua inglesa fosse organizado a partir do livro didático Alive! ${ }^{13}$, que era o principal material usado nas aulas, a professora informou que costumava trazer assuntos de outras disciplinas, visto que isso era facilitado pelo próprio material didático.

A turma escolhida para a realização do projeto foi um sexto ano composto por 26 alunos, com idades entre 11 e 15 anos. É importante salientar que era o primeiro ano em que os alunos teriam aulas de inglês.

\section{As etapas do projeto}

Durante a observação das aulas, os alunos responderam a um questionário sobre si e sobre as experiências prévias com o inglês. Através das observações, das informações obtidas pelo questionário e das conversas informais com os professores, foram definidos o eixo temático e a problematização geral do projeto, etapa que, segundo Schlatter \& Garcez (2012), deve ser feita conjuntamente entre os professores que pretendem trabalhar interdisciplinarmente.

${ }^{13}$ MENEZES, Vera. et al. Alive! : inglês, $6^{\circ}$ ano. $1^{\text {a }}$ ed. São Paulo: Editora Anzol, 2012. 


\subsection{Conhecimento de campo}

Através das observações, constatou-se que os alunos gostavam muito de interagir verbalmente em inglês, principalmente de falar. Nas aulas em que havia interlocução em inglês, ficavam mais atentos, respondiam, questionavam e mostravam-se interessados. Era uma turma bastante agitada que parecia gostar de atividades que exigiam movimento ou algum tipo de deslocamento.

Para complementar as observações, foi aplicado um questionário com o intuito de conhecer melhor os alunos e suas experiências com inglês e com abordagens interdisciplinares. Os estudantes deviam avaliar, em uma escala de 1 a 5 (sendo 1 de menor valor e 5 de maior valor), o quanto gostavam de inglês, o quanto gostavam das aulas de inglês, o quanto gostavam de ver inglês em outras disciplinas da escola e o quanto gostavam das aulas de artes. O gráfico abaixo apresenta os dados obtidos.

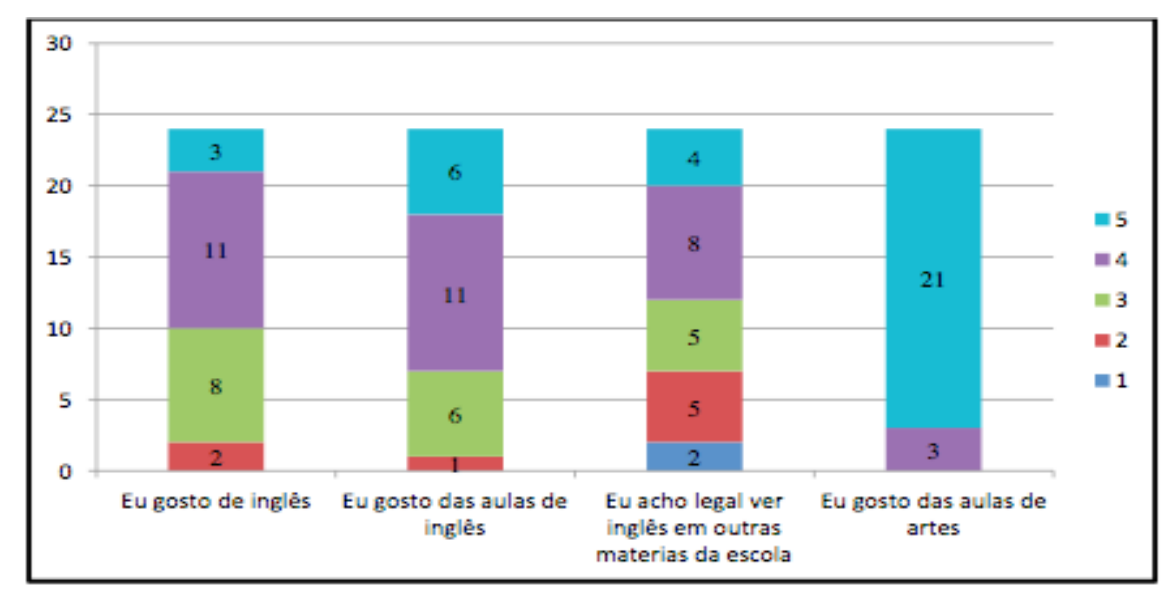

Gráfico 1 - Dados obtidos com a aplicaçằ do questionário

Como se depreende do gráfico 1, dos 24 alunos que responderam ao questionário, 11 avaliaram a frase "eu gosto de inglês" na escala 4 e 17 disseram gostar ou gostar muito de inglês. Quanto à possibilidade de ver inglês em outras disciplinas, o resultado foi mais diversificado: oito estudantes marcaram a escala 4, cinco marcaram a 3 e outros cinco marcaram a 2. Sobre as aulas de artes, porém, houve pouca variação: 21 alunos disseram gostar muito, e os outros três disseram gostar das aulas.

Como mencionado, era o primeiro ano em que os alunos tinham aulas de inglês. Entretanto, muitos disseram ter contato com a língua em outros contextos, como em músicas, seriados, jogos e redes sociais. Os alunos contaram que dois ou mais professores já haviam trabalhado em conjunto com a turma e que a experiência havia sido "bem legal", "divertida" e "aprimorou o inglês". O trabalho, nesse caso, consistiu em assistir ao filme Marley \& eu, em inglês e com legendas.

\subsection{Construção da sequência didática e organização das aulas}

O projeto foi desenvolvido em 11 aulas de inglês e três aulas de artes, no período de 31 de agosto a 09 de novembro de 2016. O primeiro passo para a elaboração da sequência didática foi decidir, em conjunto com a professora de artes, o tema e o produto final do projeto. Com essas decisões tomadas, foram elaboradas as tarefas para a disciplina de inglês. A seguir, estão descritas as etapas e aulas do projeto conforme o planejamento. São descritas também as aulas da disciplina de artes que foram parte do projeto. 


\subsubsection{Escolha do tema e do produto final}

Quando se pretende trabalhar com projetos e de modo interdisciplinar, há de se tomar "decisões interdisciplinares gerais" (SCHLATTER \& GARCEZ, 2012), as quais compreendem o eixo temático do projeto, a problematização geral e, às vezes, a seleção de textos de interesse geral. No caso presente, o eixo temático escolhido foi as artes cênicas. $O$ objetivo foi desenvolver nos alunos a capacidade de entender e expressar histórias através de diferentes linguagens: a linguagem verbal, oral e escrita, e a linguagem corporal.

O produto final constituiu-se, portanto, da encenação de uma história escrita pelos alunos e da elaboração de uma coletânea contendo os roteiros dessas histórias. Em regra, a linguagem verbal foi trabalhada nas aulas de inglês, enquanto as aulas de artes deram ênfase à linguagem e expressão corporal. A rigor, tal divisão funcionou para guiar estudantes e professores a respeito de qual habilidade estaria recebendo mais atenção em qual aula (se a fala na aula de inglês ou a expressão corporal na aula de artes, por exemplo). Isso porque, na prática, ambas as competências tendem a se misturar e os alunos estariam utilizando os conhecimentos trabalhados em uma aula para atingir os objetivos da outra. Nos ensaios realizados na aula de inglês, por exemplo, a ênfase foi na linguagem, mas os alunos utilizaram os conhecimentos adquiridos na aula de artes para realizar a tarefa.

\subsubsection{Apresentação (aulas 1 e 2)}

A primeira aula teve o objetivo de explicar que o projeto envolveria a criação de um produto final em inglês e que a avaliação seria feita aula a aula. Para a introdução do tópico, foi desenvolvido um jogo de forca com três palavras-chave em inglês, as quais eram relevantes para o andamento do projeto: Projeto, Respeito e Responsabilidade.

A segunda aula teve por objetivo familiarizar os alunos com a linguagem de sala de aula, como solicitar permissão para sair da sala ou questionar a pronúncia ou significado de alguma palavra, com vistas a proporcionar interlocução efetiva na língua adicional.

\subsubsection{Tarefas de preparação (aula 3)}

A terceira aula foi dedicada a tarefas de preparação para compreender uma cena de um filme, com foco no vocabulário relacionado às artes cênicas. O propósito era proporcionar o primeiro contato dos alunos com o vocabulário, preparando-os tanto para as tarefas de estudo do texto a serem realizadas nas aulas seguintes quanto para a produção final. Como modelo, foi escolhida uma cena do filme Gone with the Wind ${ }^{14}$, de 1939. A atividade proposta para esse dia está no quadro 2 .

\begin{tabular}{|lll|}
\hline ( ) theatre & ( ) atuar & ( ) collaborative form of art, with \\
actors and actress \\
( ) impression & ( ) papel & ( ) the stage representation of a story \\
( ) role & ( ) peça & ( ) a person of a drama or novel \\
( ) stage & ( ) personagem & ( ) performing the role of a character in \\
( ) play & ( ) teatro & ( ) a part that the actor has in a play \\
( ) character & ( ) cenário & ( ) the view, the place \\
( ) acting & ( ) imitação & ( ) the platform where the performers \\
( ) scenery/setting & ( ) palco & ( ) an imitation
\end{tabular}

Quadro 2 - Atividade para aula 3

${ }^{14}$ Disponível em: https://www.youtube.com/watch?v=xLnTWxpTQt4. Acesso em 12 de setembro de 2018. 


\subsubsection{Estudo do texto (aulas 4 e 5)}

As tarefas de estudo do texto ocorreram entre nas aulas 4 e 5 e envolveram compreender e reagir a uma cena clássica do cinema, inclusive reproduzindo-a. O objetivo da aula 4 foi desenvolver a compreensão oral, através da cena de Gone with the Wind da aula anterior e de outro vídeo ${ }^{15}$ em que 29 atores reproduzem as mesmas falas contidas na cena, cada um à sua maneira. A tarefa proposta se encontra no quadro 3.

\section{Assista ao video e marque R para Rhett, S para Scarlett e N para No one:
( ) is desperate
( ) is the man
( ) is smiling
( ) is crying
( ) is leaving
( ) is the woman
( ) is hopeless
( ) is happy

Quadro 3 - Atividade para aula 4.

A aula 5 teve o propósito de trabalhar determinadas estruturas gramaticais para entender as frases da cena do filme em seu contexto. A intenção era desenvolver também as habilidades de produção e expressão oral dos alunos, conjugando a pronúncia do inglês com a encenação das falas.

\subsubsection{Preparação para o produto final (aula 6)}

A sexta aula foi de preparação da elaboração do produto final. O objetivo dessa aula foi familiarizar os alunos com a escrita, em inglês, de diálogos a serem encenados. A tarefa proposta consistiu em conduzir os alunos à criação de um diálogo para uma cena já existente. Foram escolhidas cenas de Marley \& eu, Game of Thrones e The Walking Dead. A proposta também serviu para revisar recursos linguísticos presentes nas cenas que já haviam sido trabalhados em aulas anteriores.

\subsubsection{Elaboração do produto final (aulas 7, 8, 9, 10 e 11)}

A elaboração do produto final ocorreu entre as aulas 7 e 11. Esta etapa teve o propósito de formar os grupos de trabalho e iniciar a escrita dos diálogos, em português. Nestas aulas os alunos escreveram o diálogo, confeccionaram a coletânea de histórias a ser incluída no acervo da biblioteca, e ensaiaram as apresentações.

$\mathrm{Na}$ aula de Artes, a professora solicitou que os grupos pensassem em duas palavras importantes no diálogo para fazer parte da performance. Durante a apresentação dos grupos, as palavras seriam usadas para interferir na performance. Para o projeto, a ênfase em aprender sobre performance era útil para aprimorar a apresentação teatral dos alunos.

$\mathrm{Na}$ aula 8, as atividades foram centradas na escolha dos personagens e no cenário da história. Além disso, os alunos realizaram uma tarefa que solicitava a produção de um resumo de uma linha do roteiro (como uma sinopse), em inglês, para facilitar que possíveis leitores escolhessem a história futuramente. Por ocasião da segunda aula de artes dedicada ao projeto, os alunos formaram os grupos da apresentação de inglês e trabalharam com as palavras importantes que haviam escolhido na aula anterior.

\footnotetext{
${ }^{15}$ Disponível em: https://www.youtube.com/watch?v=uFW2bmReOq0. Acesso em 12 de setembro de 2018.
} 
$\mathrm{Na}$ aula seguinte e com os diálogos prontos, os alunos trabalharam na criação do título do livro e escreveram uma introdução, definindo o público-alvo das histórias e criando, por iniciativa própria, uma classificação indicativa. A turma mostrou muito comprometimento com essas tarefas, o que foi possibilitado pela clareza do objetivo da aula (escrever a introdução) aliada à coletividade do texto.

As próximas duas aulas (uma de artes e uma de inglês) foram utilizadas para os ensaios. Nos ensaios, era preciso aprender as falas para colocá-las no contexto do teatro, mesmo que não tivéssemos estudado todas as estruturas gramaticais ou aprendido todas as regras de pronúncia.

\subsubsection{Apresentações e fechamento (aulas 12 e 13)}

As aulas 12 e 13 foram destinadas às apresentações e ao fechamento, com discussão da avaliação e aplicação de uma autoavaliação. A ordem das apresentações foi definida por sorteio das palavras-chave dos grupos, funcionando como o sinal de que era a vez de aquele grupo apresentar. Para os grupos em que algum integrante estivesse ausente, outro aluno se prontificou a desempenhar o papel, de modo que todos os diálogos foram encenados na íntegra.

Para o fechamento, os alunos avaliaram individualmente o projeto, respondendo de que tinham gostado e o que haviam aprendido. Em seguida, compartilharam suas reflexões com o grupo. O planejamento está esquematizado no quadro 4.

\begin{tabular}{|l|l|l|}
\hline Etapa & Aula & Planejamento \\
\hline Apresentação & 1 & Introdução ao projeto \\
\cline { 2 - 3 } & 2 & Ensino da linguagem de sala de aula \\
\hline Tarefas de preparação & 3 & $\begin{array}{l}\text { Foco no vocabulário das artes cênicas necessário } \\
\text { para compreender o título do texto e escrever o } \\
\text { próprio produto final }\end{array}$ \\
\hline Estudo do texto & 4 & $\begin{array}{l}\text { Compreensão do vídeo e da fala de um dos } \\
\text { personagens }\end{array}$ \\
\hline Preparação do produto final & 6 & $\begin{array}{l}\text { Estudo da fala do outro personagem e reação ao } \\
\text { vídeo }\end{array}$ \\
\hline Produção do produto final & 7 & Criação de diálogo para uma cena \\
\cline { 2 - 4 } & 8 & Definição dos grupos e início da escrita do diálogo \\
\hline & 9 & Término da escrita do diálogo \\
\hline & 10 e 11 & Ensaios \\
\hline Apresentação e fechamento & 12 & Apresentações \\
\cline { 2 - 3 } & 13 & Fechamento \\
\hline
\end{tabular}

Quadro 4 - Planejamento das aulas

As tarefas se justificaram em torno da confecção do produto final (SCHLATTER \& GARCEZ, 2009) e a sequência didática partiu das práticas mais simples para as mais complexas. Pode-se notar a evolução na complexidade das tarefas planejadas: de início, os alunos precisaram compreender uma cena, depois encená-la. Mais tarde, foi necessário que eles pensassem em um diálogo para uma cena já pronta. Finalmente, eles criaram tanto a cena quanto o diálogo, e encenaram suas produções. 


\subsubsection{Critérios de avaliação}

Em busca de uma avaliação somativa, isso é, que considerasse o processo de desenvolvimento do projeto e, ao mesmo tempo, se centrasse no produto final (DOLZ et al, 2004 e HERNANDEZ, 2014), a avaliação foi organizada da seguinte forma: a avaliação do produto final, que substituiu aquela geralmente obtida através de uma prova; e a avaliação da participação em aula.

A avaliação do produto final correspondeu a $70 \%$ da nota total dos alunos, e levou em conta majoritariamente a apresentação final, depois dos ensaios e de todo o processo. Durante a produção dos alunos, os critérios de avaliação foram propostos, debatidos e esclarecidos, sendo os seguintes: (i) o grupo deveria definir o enredo da história, (ii) todos os participantes deveriam ter falas, (iii) os integrantes deveriam falar de forma clara, (iv) o tempo máximo de dez minutos deveria ser respeitado. Os alunos que assistiam às apresentações também eram responsáveis por avaliar quem estivesse apresentando, nos critérios (ii) e (iv).

Os demais $30 \%$ da nota final corresponderam à participação e ao engajamento no projeto; nesse caso, os alunos foram avaliados aula a aula, da seguinte maneira:

- Atendeu satisfatoriamente: participou da aula e fez a maioria das atividades propostas na aula;

- Atendeu parcialmente: participou pouco da aula e/ou realizou poucas das atividades propostas;

· Não atendeu: embora presente, não participou da aula nem realizou as atividades propostas;

- Ausente: aluno que não compareceu a aula.

\section{Avaliação do projeto pelos alunos}

Para as primeiras perguntas da avaliação, foram utilizadas as mesmas do questionário inicial, o que possibilitou comparar os resultados antes e depois das aulas. Abaixo, será apresentada a comparação dos resultados do questionário inicial e final.

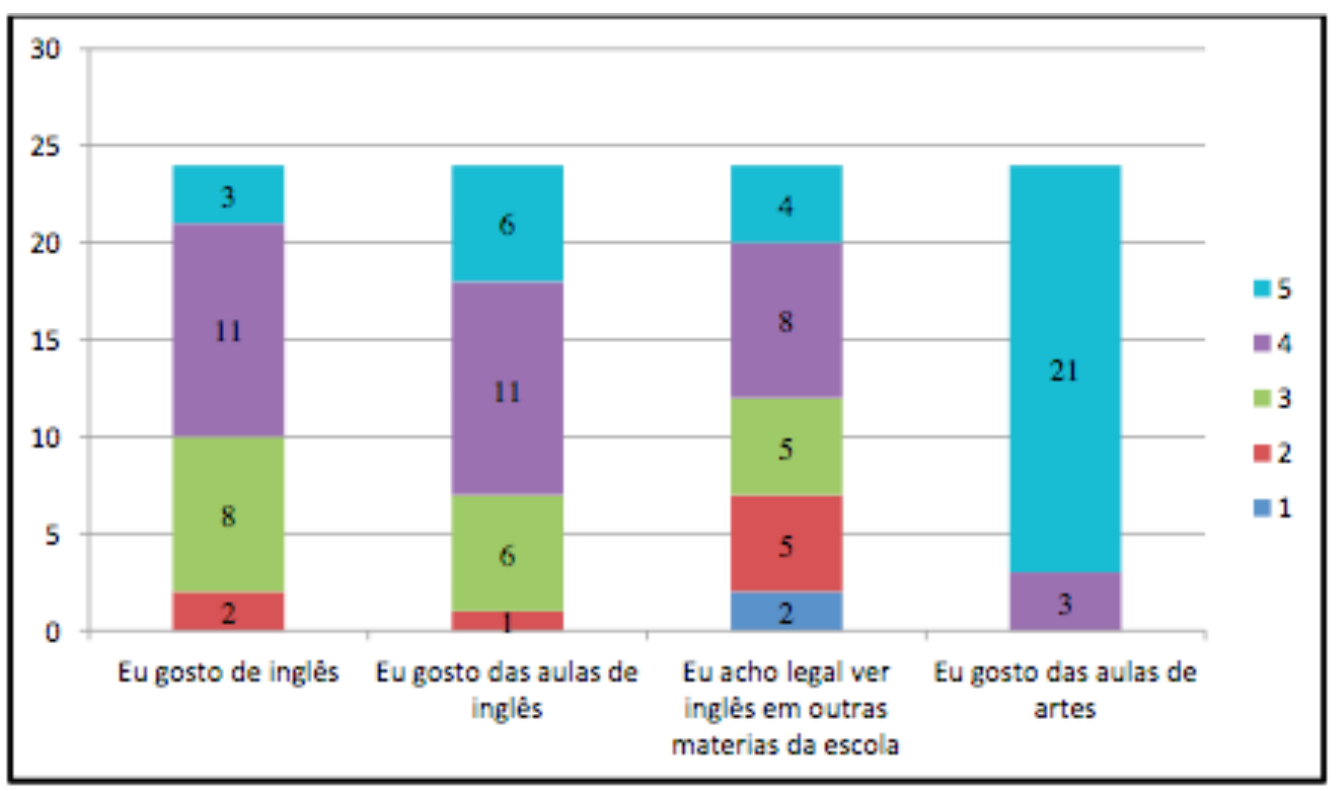




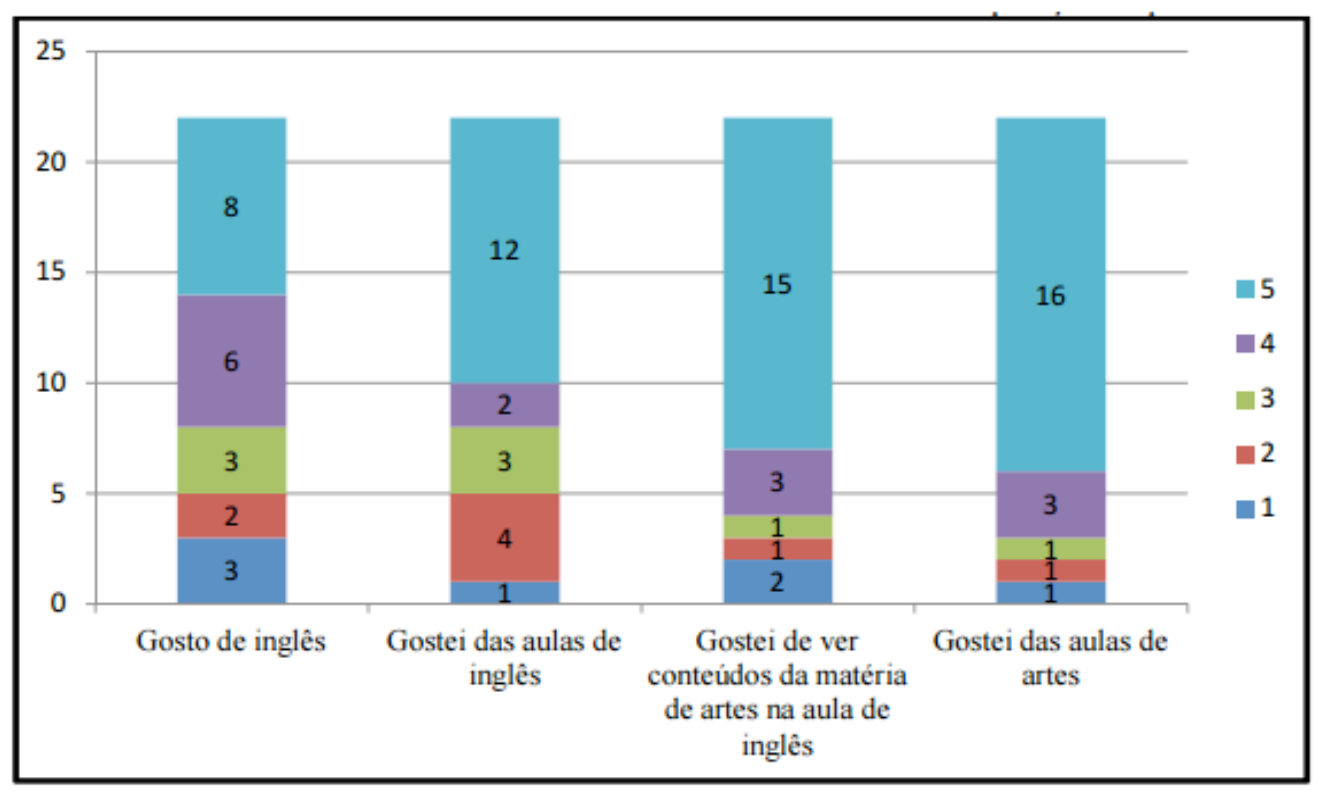

Gráfico 2 - Dados obtidos com aplicação da avaliação discente do projeto

Conforme o gráfico 2, dos 22 alunos que responderam o questionário final, 12 avaliaram a frase "gostei das aulas de inglês" na escala 5, número inclusive maior do que o de alunos que avaliaram a frase "gosto de inglês" na mesma escala. A maior diferença com relação ao questionário inicial encontra-se na terceira pergunta: no final do projeto, 15 alunos disseram ter gostado da interdisciplinaridade entre inglês e artes. A diferença pode ser creditada, talvez, ao fato de que no final do projeto os alunos tinham uma ideia mais concreta do que era "ver conteúdos de outras matérias na aula de inglês" do que na primeira aula. Além de tais perguntas, os alunos precisavam dizer de que mais haviam gostado e de que menos haviam gostado nas aulas. Deveriam também refletir sobre o que haviam aprendido e o que haviam achado de estudar artes e inglês de forma interdisciplinar.

Quanto ao que os alunos mais haviam apreciado nas aulas, a maioria dos alunos relatou ter gostado do teatro e de aprender palavras novas. Um aluno gostou de apresentar e outra aluna citou as aulas com vídeo. Dois alunos mencionaram a interação com o professor.

Alguns citaram as conversas paralelas, que dificultavam o andamento da aula, como um dos fatores de que menos gostaram nas aulas. Dois alunos mencionaram a questão da falta de tempo para as atividades. Um aluno disse não ter gostado de memorizar as falas. Escrever o diálogo foi apontado por outro estudante, assim como ter que apresentar. Em relação ao que os alunos aprenderam em aula, a maioria respondeu um pouco de inglês, ou algumas palavras novas em inglês. Alguns disseram que aprenderam a atuar e a representar.

Com relação ao que os alunos aprenderam sobre teatro e performance, alguns lembraram das palavras-chave do projeto (projeto, responsabilidade e respeito) e outros citaram as palavras aprendidas nos diálogos. Um aluno relatou ter aprendido a ter menos desinibição e outro informou ter aprendido a atuar. Uma aluna escreveu, em inglês, que aprendeu que o teatro é uma ação. No que se refere a estudar artes e inglês conjuntamente, a maioria das respostas foi positiva. Apenas uma aluna informou que preferia ter as matérias separadas; os demais avaliaram a experiência como "muito legal", "muito boa", etc. O quadro 6 reúne as respostas dos alunos. 


\begin{tabular}{|l|l|}
\hline Questões propostas aos alunos & Respostas \\
\hline De que eu mais gostei nas aulas & - ensaiar o teatro; \\
- aprender palavras; \\
- aprender mais sobre inglês e artes; \\
- apresentar; \\
- ir nas aulas na sala de vídeo; \\
- que o professor interage com a gente.
\end{tabular}

Quadro 5 - Respostas dos alunos à avaliação do projeto

Em geral os alunos avaliaram o projeto de forma positiva. Algumas respostas mostraram conexão direta com conteúdos específicos do projeto, como vocabulário e a prática de teatro. Outros ressaltaram aspectos mais gerais, como ter aprendido a ser menos inibido. A abordagem por projetos possibilita esse alcance mais abrangente, já que trabalha de forma integrada diversas competências. Alguns alunos ressaltaram a interação entre professor e aluno como aspecto positivo das aulas, assim como a interação em inglês entre os próprios alunos. Essa interação também é facilitada pela abordagem dos projetos, já que tanto os alunos quanto o professor precisam trabalhar de forma colaborativa para resolver as questões.

Quanto aos aspectos negativos, a maioria das respostas estava relacionada às conversas paralelas na aula. Esse aspecto mostrou uma diferença significativa entre as aulas realizadas durante do projeto e as aulas anteriores. Para o bom desenvolvimento do projeto, era necessário que os alunos conversassem mais entre si do que durante as aulas anteriores. Inevitavelmente, isso acarretou mais barulho na sala. Um aluno disse não ter gostado de memorizar as falas, outro mencionou não ter gostado de escrever a história.

Com relação à abordagem interdisciplinar, a maioria dos alunos relatou ter gostado das aulas, alguns citando o aspecto divertido conferido às atividades, outros mencionando que os componentes curriculares combinam. Uma aluna relatou ter gostado um pouco, mas disse que preferia ter as disciplinas de forma separada. 


\section{Considerações finais}

Este artigo apresentou o desenvolvimento de uma sequência didática para o ensino de inglês considerando as metas definidas em Schlatter e Garcez (2012) para o currículo de língua adicional: promover o autoconhecimento, o letramento e a interdisciplinaridade. Evidenciou-se, também, o caráter flexível e colaborativo dos projetos de aprendizagem (Hernandez, 2014; Barbosa, 2001; Simões, 2012), visto que foi necessário ajustar as áreas em que os alunos precisavam de mais atenção e repensar o produto final para melhor ajustá-lo ao contexto. Dessa forma, como proposto por Schlatter e Garcez (2009), a confecção do produto final foi o que justificou as tarefas da sequência didática. A avaliação foi formativa na medida em que considerou o processo de construção dos textos teatrais e o desenvolvimento dos alunos. Os textos foram produzidos dentro de um contexto, assim incluindo a representação da situação de comunicação que se queria dominar e subordinando os instrumentos linguísticos necessários para atingir os objetivos propostos.

Um dos objetivos alcançados por este projeto foi o de capacitar os alunos a utilizarem a língua inglesa em situações do cotidiano escolhidas por eles, uma vez que escreveram com base em suas vivências, partindo de uma linguagem conhecida com destino à produção na língua adicional. Outro objetivo atingido foi desenvolver o letramento e a consciência dos alunos de modo a ampliar sua participação em práticas sociais em que a língua inglesa é utilizada. Entendendo letramento como "a participação em diferentes práticas sociais que envolvem a leitura e a escrita" (SCHLATTER, 2009, p. 12), pode-se considerar que desenvolver os textos teatrais e encená-los constituiu uma prática social que envolveu tanto a língua materna quanto a adicional: ao final do projeto, os alunos estavam mais familiarizados com o gênero cena de teatro.

A interdisciplinaridade é definida como forma de organizar os currículos escolares de modo a integrar as disciplinas (GALLO, 1995). Nesse sentido, o projeto aqui relatado teve caráter interdisciplinar, com o esforço docente conjunto para que essa integração ocorresse minimizando a compartimentalização dos saberes e possibilitando experiências enriquecedoras de trocas. A abordagem interdisciplinar traz benefícios para alunos e professores, que ensinam e aprendem a mobilizar saberes relevantes de diferentes áreas, muitas vezes de forma autônoma, para resolver questões que fogem à compartimentalização das disciplinas, produzindo conhecimento pertinente e contextualizado (MORIN, 2000).

\section{Referências}

BARBOSA, Maria Carmem Silveira. Por que voltamos a falar e a trabalhar com a pedagogia de projetos? 2001. Projeto - Revista de Educação, vol. 3, nº 4, p. 8-13.

BIONDO, Fabiana Poças. As diferentes versões de uma história única: a polêmica a respeito do livro didático Por uma vida melhor e os estudos do(s) letramento(s). Trabalhos em

Linguística Aplicada. Campinas, vol. 51, no 1, p. 245-260. 2012. Disponível em: http://www.scielo.br/pdf/tla/v51n1/v51n1a13.pdf. Acesso em 12 set. 2018.

DIAS, Eliana; MESQUITA, Elisete Maria de Carvalho; FINOTTI, Luísa Helena Borges; OTONI, Maria Aparecida Resende; LIMA, Maria Cecília de; ROCHA, Maura Alves de Freitas. Gêneros textuais e(ou) gêneros discursivos: uma questão de nomenclatura? 2011. Intearcções, $n^{\circ}$ 9, p. 142-155. Disponível em:

http://revistas.rcaap.pt/interaccoes/article/viewFile/475/429. Acesso em: 12 set. 2018.

DOLZ, Joaquim. NOVERRAZ, Michèle, SCHNEUWLY, Bernard. Sequências didáticas para o oral e a escrita: apresentação de um procedimento. In: DOLZ, Joaquim, SCHNEUWLY, Bernard (e colaboradores). Gêneros orais e escritos na escola. Tradução de Roxane Rojo. 2004. São Paulo, Mercado das Letras. p. 81-108. 
GALLO, Sílvio. Conhecimento, transversalidade e currículo. 1995. Disponível em: http://www.academia.edu/518339/Conhecimento_transversalidade_e_curriculo. Acesso em: 12 set. 2018.

GALLO, Sílvio. Currículo (entre) imagens e saberes. 2007. Disponível em: http://www.grupodec.net.br/ebooks/GalloEntreImagenseSaberes.pdf. Acesso em: 12 set. 2018. HERNANDEZ, Fernando. Entrevista com o Professor Fernando Hernandez. 2014. Revista Bem Legal, vol. 4, no 1, p. 65-72.

HERNANDEZ, Fernando. Os projetos de trabalho: um mapa para navegantes em mares de incerteza. 2001. Projeto - Revista de Educação, vol. 3, nº 4, p. 2-7.

MORIN, Edgar. A antiga e a nova transdisciplinaridade. In: . Ciência com Consciência. Tradução de Maria D. Alexandre e Maria Alice Sampaio Dória. 2005. Rio de Janeiro, Bertrand Brasil, $8^{\mathrm{a}}$ Ed. revista e modificada pelo autor. p. 136-140.

MORIN, Edgar. O desafio da complexidade. In: Ciência com Consciência. Tradução de Maria D. Alexandre e Maria Alice Sampaio Dória. 2005. Rio de Janeiro, Bertrand Brasil, $8^{a}$ Ed. revista e modificada pelo autor. p. 175-193.

MORIN, Edgar. Os sete saberes necessários à educação do futuro. Tradução de Catarina Eleonora F. da Silva e Jeanne Sawaya. 2000. 2ª Ed. São Paulo, Cortez; Brasília, DF : UNESCO.

SCHLATTER, Margarete. O ensino de leitura em língua estrangeira na escola: uma proposta de letramento. Calidoscópio, vol. 7, no 1. jan/abr 2009. p 11-23.

SCHLATTER, Margarete; GARCEZ, Pedro de Moraes. Línguas adicionais (espanhol e inglês). Referenciais Curriculares do Estado do Rio Grande do Sul: Linguagens, Códigos e suas Tecnologias. Porto Alegre, 2009, v. 1, p. 127-172.

SCHLATTER, Margarete; GARCEZ, Pedro de Moraes. Línguas Adicionais na escola: aprendizagens colaborativas em inglês. 2012. Erechim, Edelbra. Coleção Entre Nós - anos finais do ensino fundamental.

SIMÕES, Luciene Juliano. Leitura e autoria: planejamento em Língua Portuguesa e Literatura. Colaboração de Ana Maria Filipouski, Diana Marchi e Joice Welter Ramos. 2012. Erechim, Edelbra. Coleção Entre Nós - anos finais do ensino fundamental.

WELP, Anamaria Kurtz de Souza; VIAL, Ana Paula Seixas. Currículo com base em projetos pedagógicos: relato de uma experiência a educação superior. Revista Entrelinhas. jul/dez 2016. p. 230-254.

Submetido em 26/09/18

Aceito em 17/12/2018 